\title{
Which One Is More Important to Being a Good Family Physician for Medical Students, Disease Diagnosis or Patient- Doctor Relationship?

\author{
Mohamed Amin Ghobadifar*
}

Department of Student Research Committee, Jahrom University of Medical Sciences, Jahrom, Iran

\section{Dear Editor,}

We all understand the importance of the doctor-patient relationship, as doctors. Sometimes this relationship can be much more useful than complicated procedures or diagnostic tests. ${ }^{1,2)}$ As much as patients need treatment, many of them need emotional support from their physicians. Maybe it seems irrational, but prognosis and outcome of disease can occur because of the patientphysician relationship. ${ }^{3)}$ Hence, due to improving outcomes in medical practices, developing our relationship with patients is our obligation.

I was observing patients in my clinic on a warm day in the summer of 2012. It was around the afternoon when Sarah and her father came in. Sarah was a sweaty 16-year-old girl. Since Sarah was 10 years old, I had been her family's family doctor and I knew them well over these years. That day Sarah seemed sick, which was unusual for her. Her chief complaint was blunt pain in her left knee which had started about two weeks ago. She also

*Corresponding Author: Mohamed Amin Ghobadifar

Tel: +98-936-620-8078, Fax: +98-711-636-1386

E-mail:amin_m505@yahoo.com

Korean Journal of Family Medicine

Copyright (C) 2013 The Korean Academy of Family Medicine

(a) This is an open-access article distributed under the terms of the Creative Commons Attribution Non-Commercial License (http://creativecommons.org/licenses/by-nc/3.0) which permits unrestricted noncommercial use, distribution, and reproduction in any medium, provided the original work is properly cited. suffered from an intermittent, low-grade fever. An irregularity in the anterior side of her left tibia was observed during the physical examination. I ordered a radiographic scan of the left limb for better evaluation. The radiologist reported a central osteolytic tumor in the left tibial metaphysis which expanded toward the knee. An increased level of erythrocyte sedimentation rate and mild leukocytosis were detected in her blood test. How is it possible to tell a 16-year-old girl that she likely has bone cancer? I was at a loss as to what to tell her. Therefore, I decided to say nothing. "Maybe it is not important," I told her. "Nevertheless I will refer you for better evaluation to an orthopedic surgeon".

Sarah returned with her mother and father a month later. It was clear that the surgeon told them the tragic news. They recounted the experiences of the past month with downcast faces. Sarah had gone under bone biopsy which is a painful and uncomfortable procedure for both adult and child patients. Her father gave me a bulk of sheets including immunohistochemistry and pathology reports and a plan for treatment. As I had suspected, the results determined that she had Ewing sarcoma. The treatment plan was transfemoral amputation followed by 5 courses of radiotherapy. Among the bulk of papers, I found a request from the orthopedic surgeon asking me to explain the situation to Sarah and her parents and prepare them psychologically for the operation.

I felt a difficult task was ahead of me. I explained the indications of the tumor briefly and requested they collaborate with the surgeon in order to obtain the best outcome. "Sometimes we have to sacrifice valuable things to receive more important goals" I said. That is what Sarah had to do. To save her life, she 
had to lose her limb. However this would not be simple. Sarah was a fresh and young girl who had never faced to any important problems in her life. These small cancerous cells became the biggest obstacle in her life. It was an uncomfortable conversation between us and I wasn't sure that I had convinced them to follow the plan for treatment. They shook their heads. "Certainly you are mistaken?" Then they left my clinic in deep grief.

I didn't see Sarah again until she and her family walked into my clinic almost 4 months later. On the contrary, her limb had been saved. She couldn't walk without help and seemed cachectic. Her mother began crying and said that it had been impossible for them to accept such an operation, when I asked why Sarah hadn' t had the operation yet. They hadn't followed the orthopedic surgeon. They had traveled abroad to find an alternative approach but after spending 2 months they had found the same treatment plan: amputation. During the last days before they returned to me, Sarah developed hemoptysis and dyspnea. The metastasis to her lungs was found by a radionucleotid scan. There were no treatment plans now. Sarah was admitted to the hospital for palliative care and she passed away 3 weeks later. In the last moment of Sarah's life, I will never forget the expression on her pretty face. She asked me to not let this kind of thing happen again. She left profound sorrow in my heart and left this world at last. Sarah's family might have trusted my advice if we had had a stronger relationship. Sarah taught me about the essential role of trust in patient-doctor relationship and how serious and important this relationship can be. Sarah lives on in my stronger relationships with other patients as she keeps on reminding me how to be a reliable and better physician.
The above history clearly indicates the importance of physician-patient relationship. Physicians should always keep a strong relationship with their patients instead of just focusing on diagnosis. There are too many unanswered questions about the importance of the doctor-patient relationship for medical students, in spite of a significant amount of research. Therefore, it seems critical to develop more training programs which teach medical students about the importance of the patient-doctor relationship.

Yours Sincerely

\section{CONFLICT OF INTEREST}

No potential conflict of interest relevant to this article was reported.

\section{REFERENCES}

1. Lucchiari C, Pravettoni G. The role of patient involvement in the diagnostic process in internal medicine: a cognitive approach. Eur J Intern Med 2013;24:411-5.

2. Dixon T. Doctors, patients and relationships. Can Fam Physician 1989;35:9-15.

3. Gill DG, Horobin GW. Doctors, patients and the state: relationships and decision-making. Sociol Rev 1972;20:50520. 